\title{
Relationship of Self-Reported Asthma Severity and Urgent Health Care Utilization to Psychological Sequelae of the September 11, 2001 Terrorist Attacks on the World Trade Center Among New York City Area Residents
}

\author{
Joanne Fagan, PhD, Sandro Galea, MD, DrPH, Jennifer Ahern, MPH, Sebastian Bonner, PhD, and \\ David Vlahov, PhD
}

\begin{abstract}
Objective: Posttraumatic psychological stress may be associated with increases in somatic illness, including asthma, but the impact of the psychological sequelae of the September 11, 2001 terrorist attacks on physical illness has not been well documented. The authors assessed the relationship between the psychological sequelae of the attacks and asthma symptom severity and the utilization of urgent health care services for asthma since September 11. Materials and Methods: The authors performed a random digit dial telephone survey of adults in the New York City (NYC) metropolitan area 6 to 9 months after September 11, 2001. Two thousand seven hundred fifty-five demographically representative adults including 364 asthmatics were recruited. The authors assessed self-reported asthma symptom severity, emergency room (ER) visits, and unscheduled physician office visits for asthma since September 11. Results: After adjustment for asthma measures before September 11, demographics, and event exposure in multivariate models posttraumatic stress disorder (PTSD) were a significant predictor of self-reported moderate-to-severe asthma symptoms $(\mathrm{OR}=3.4 ; \mathrm{CI}=1.2-9.4)$, seeking care for asthma at an ER since September $11(\mathrm{OR}=6.6$; $\mathrm{CI}=1.6-28.0)$, and unscheduled physician visits for asthma since September $11(\mathrm{OR}=3.6 ; \mathrm{CI}=1.1-11.5)$. The number of PTSD symptoms was also significantly related to moderate-to-severe asthma symptoms and unscheduled physician visits since September 11. Neither a panic attack on September 11 nor depression since September 11 was an independent predictor of asthma severity or utilization in multivariate models after September 11. Conclusions: PTSD related to the September 11 terrorist attacks contributed to symptom severity and the utilization of urgent health care services among asthmatics in the NYC metropolitan area. Key words: asthma, disaster, mental health, posttraumatic stress.
\end{abstract}

NYC $=$ New York City; PTSD $=$ posttraumatic stress disorder; $\mathbf{W T C}=$ World Trade Center; RDD $=$ random digit dial; $\mathbf{E R}=$ emergency room.

\section{INTRODUCTION}

Several studies have shown a substantial prevalence of $S_{\text {psychological symptoms including major depression and }}$ posttraumatic stress disorder (PTSD) in the general population of New York City (NYC) after the events of September 11 $(1,2)$. In addition, exposure to dust, smoke, and odors from the fires that burned at the site for several weeks exacerbated respiratory symptoms in many residents and workers (3-7), including persons with asthma. While the effects of the terrorist attacks on the World Trade Center (WTC) on mental $(1,2)$ and physical $(3-7)$ health are the topic of a number of ongoing studies, the impact of psychological stress associated with these attacks on somatic illnesses and symptoms has received relatively little attention.

We have previously reported that both the environmental and psychological sequelae of the September 11 attacks were associated with increasing symptoms experienced by some persons with asthma 1 month after the attacks (5). Here we report findings from a survey assessing the relations between the psychological sequelae of the attacks and self-reported

From Center for Urban Epidemiologic Studies, New York Academy of Medicine, 1216 Fifth Avenue, New York City, NY 10029.

Address correspondence and reprint requests to Sandro Galea, MD, DrPH, Center for Urban Epidemiologic Studies Room 556, New York Academy of Medicine, 1216 Fifth Avenue, New York, NY 10029-5283. E-mail: sgalea@nyam.org

Received for publication February 24, 2003; revision received June 11, 2003.

Supported by grants from the United Way of New York City and the New York Community Trust, the commonwealth Fund, the MetLife Foundation, the National Institute on Drug Abuse of the National Institute of Health (RO1 DA14219-01S1), and the National Institute of Mental Health (RO1 MH66081010). The authors acknowledge the assistance of Dr. Thomas Matte.

DOI: 10.1097/01.PSY.0000097334.48556.5F asthma symptom severity and health care utilization for asthma since September 11, 2001 to see if these relationships were present 6 months after the event.

\section{MATERIALS AND METHODS}

We conducted a random digit dial (RDD) household survey between March 25 and June 25, 2002. The sampling frame included all adults in the NYC metropolitan area; for sampling purposes, we sampled equal numbers of people from four sampling zones radiating concentrically out from the WTC site (eg, the first zone included only Manhattan south of 14th Street). The overall cooperation rate, for residents where a respondent was reached, was $56.0 \%$ (based on the sum of the number of completed interviews, quota outs [ie, persons called who were in a sampling zone after we had completed quota for that zone] and screen outs [ie, persons who were not eligible for surveying, eg, persons who were visitors and not living in the area]) divided by the sum of completed interviews, quota outs, screen outs, refusals, and premature terminations (8). A total of 2755 persons were interviewed. These analyses are based on the $364(12.7 \%)$ participants who responded "yes" to "has a doctor ever told you that you have asthma?"

All interviews were conducted by trained interviewers using a computerassisted telephone interview system. Interviews were available in English, Spanish, and Chinese. Measures of post-September 11 asthma severity collected during the interview included severity of their symptoms during the past 4 weeks (moderate or severe symptoms vs. none or mild), ER visits for asthma (1 or more vs. none), and unscheduled physician office visits for asthma (1 or more vs. none) during the period since the September 11 attacks. Participants' asthma status before September 11 was assessed by asking questions addressing the severity of symptoms during the 4 weeks before September 11 (moderate or severe symptoms vs. none or mild), nighttime symptoms (1 or more nights/mo woken with symptoms vs. never woken with symptoms) and use of ER care during the 12 months before September 11 ( 1 or more vs. none).

We also asked about socio-demographic characteristics (age, gender, race/ethnicity, yearly household income, education, social support [6 mo before September 11], and sentinel life-stressors [12 mo before September 11]). Social support was assessed using three questions from the MOS social support scale, asking about emotional, instrumental, and appraisal support (9); sentinel life stressors were assessed by asking if a respondent had experienced one of eight possible significant stressors (eg, personal experience of violence, natural disaster). To assess respondent exposure to the September 11 terrorist attacks, respondents were asked whether they witnessed the attacks in person, had a friend or relative killed, lost a job because of the attacks, 
changed their smoking status, smelled unusual odors related to the attacks during the week after, and the location where they lived on September 11. Psychological syndromes assessed included peri-event panic attack using a modified version of the Diagnostic Interview Schedule (DIS) for panic attack (phrased to detect symptoms experienced during or soon after the September 11 terrorist attacks) (10). We used the National Women's Study (NWS) PTSD module to measure PTSD symptoms. The NWS PTSD module was validated in a field trial against the PTSD module of the Structured Clinical Interview for DSM-III-R (SCID) (11) administered by mental health professionals; in the field trial, interrater kappa coefficients were 0.85 for the diagnosis of lifetime PTSD and 0.86 the diagnosis of current PTSD (12). We used a modified, validated, version of the Structured Clinical Interview for DSM-IV major depressive episode questions to determine presence of depression within the past 30 days (13).

We used chi-square tests to identify bivariate associations between sociodemographic characteristics, September 11 event exposures, psychological factors, and asthma status before September 11 with each of the three post-September 11 asthma outcomes. We developed separate logistic models for each outcome that included covariates associated with the outcome at $p<$ 0.2. Each of the three psychological syndromes (peri-event panic attack, PTSD, and depression) of interest was added separately to the multivariate models to estimate the relative odds of each asthma outcome in the presence of the psychological impact, with the absence of the impact serving as the referent category. In addition, models were fit to estimate the relation of the number of PTSD symptoms to each outcome. Sampling weights were devel- oped and applied to our data when estimating proportions and odds ratios to adjust for differences in selection probabilities related to the number of household telephones, persons in the household, and over-sampling.

\section{RESULTS}

The estimated mean age of adults with asthma was 40 (SD $=21.3$ ) with $81.0 \%$ being younger than age 55 years, $61.0 \%$ were women, $53.5 \%$ were non-Hispanic whites, $28.5 \%$ had an annual household income of $\$ 40,000$ or more, $42.7 \%$ had a college or graduate degree, and $20.1 \%$ had two or more life stressors during the 12 months before September 11.

On average, more asthmatics reported moderate-to-severe symptoms in the past 4 weeks $(24.2 \%)$, compared with the 4 weeks before September 11 (14\%) (Table 1). A similar proportion reported ER visits for asthma (13.3\%) in the 6 to 9 months since September 11 compared with $17.7 \%$ during the 12 months before September 11. Among adults with asthma, 1 in 5 reported symptoms compatible with a panic attack during or soon after the September 11 attacks, 6.5\% reported symptoms compatible with PTSD since September 11, and 13.0\% demonstrated symptoms of depression since September 11.

TABLE 1. Distribution of Asthma Severity and Urgent Health Care Utilization Before and After September 11 and Psychological Outcomes after the September 11 Terrorist Attacks

\begin{tabular}{|c|c|c|}
\hline & Number ${ }^{a}$ & Percent ${ }^{b}$ \\
\hline Total & 364 & 12.7 \\
\hline \multicolumn{3}{|l|}{ Asthma status after September 11} \\
\hline \multicolumn{3}{|l|}{ Asthma symptoms past 4 weeks } \\
\hline None to mild & 273 & 75.8 \\
\hline Moderate to severe & 88 & 24.2 \\
\hline \multicolumn{3}{|c|}{ Emergency room care for asthma since September 11} \\
\hline No & 317 & 86.7 \\
\hline Yes & 45 & 13.3 \\
\hline \multicolumn{3}{|c|}{ Unscheduled physician visit for asthma since September 11} \\
\hline No & 272 & 74.8 \\
\hline Yes & 91 & 25.2 \\
\hline \multicolumn{3}{|l|}{ Asthma status before September 11} \\
\hline \multicolumn{3}{|l|}{ Before September 11 symptoms } \\
\hline None to mild & 318 & 86.0 \\
\hline Moderate to severe & 41 & 14.0 \\
\hline \multicolumn{3}{|c|}{ Nighttime symptoms 12 months before September 11} \\
\hline No nights woken & 197 & 55.0 \\
\hline 1 or more nights woken/mo & 143 & 45.0 \\
\hline \multicolumn{3}{|c|}{ Emergency room care 12 months before September 11} \\
\hline None & 315 & 82.3 \\
\hline 1 or more & 49 & 17.7 \\
\hline \multicolumn{3}{|l|}{ Psychological factors } \\
\hline \multicolumn{3}{|l|}{ Peri-event panic attack } \\
\hline No & 287 & 80.0 \\
\hline Yes & 77 & 20.0 \\
\hline \multicolumn{3}{|c|}{ Post traumatic stress disorder related to the September 11 attacks } \\
\hline No & 334 & 93.5 \\
\hline Yes & 30 & 6.5 \\
\hline \multicolumn{3}{|l|}{ Depression since September 11} \\
\hline No & 307 & 87.0 \\
\hline Yes & 49 & 13.0 \\
\hline
\end{tabular}

\footnotetext{
${ }^{a}$ Number of respondents who had ever been told by a physician that they had asthma. Numbers that do not add up to 364 for variables reflect participants with unknown or missing values.

${ }^{b}$ Percents are all weighted to account for varying probabilities of selection among respondents based on number of phone numbers, number of adults in household, and oversampling.
} 


\section{ASTHMA AND PSYCHOLOGICAL SEQUELAE OF SEPTEMBER 11}

In models unadjusted for pre-September 11 asthma measures and other covariates, all three psychological outcomes (panic attack, depression, and PTSD) after September 11 were associated with more severe asthma symptoms and with urgent health care visits for asthma since September 11; some, but not all, of these associations were greatly attenuated with adjustment for covariates (Table 2). For peri-event panic attack, significant crude associations were seen with seeking care for asthma at an ER since September $11(\mathrm{OR}=2.9$; CI $=1.2-7.5)$ and seeking unscheduled physician care for asthma since September $11(\mathrm{OR}=3.7$; CI $=1.8-7.7)$, but these associations were no longer significant when controlling for covariates $(\mathrm{OR}=1.1, \mathrm{CI}=0.4-3.4 ; \mathrm{OR}=2.0, \mathrm{CI}=$ $0.8-4.6$, respectively). Depression was not a significant predictor for any of the post-September 11 asthma outcomes in either crude or adjusted models. PTSD was a significant predictor of self-reported moderate-to-severe asthma symptoms in the unadjusted, bivariate analysis $(\mathrm{OR}=3.4 ; \mathrm{CI}=$ $1.0-10.9)$ and in the multivariate model $(\mathrm{OR}=3.4$; $\mathrm{CI}=$ 1.2-9.4). PTSD was also significantly associated with seeking care for asthma at an ER and with unscheduled physician visits in crude and adjusted models (adjusted $\mathrm{OR}=6.6 ; \mathrm{CI}=$ $1.6-28.0$ and $\mathrm{OR}=3.6 ; \mathrm{CI}=1.1-11.5$, respectively). When assessing the effect of the number of PTSD symptoms on self-reported moderate-to-severe asthma symptoms and seeking unscheduled care from a physician for asthma since September 11, the relationships were significant in the bivariate analyses $(\mathrm{OR}=1.2$ per each additional symptom; $\mathrm{CI}=$ $1.1-1.4$ and $\mathrm{OR}=1.2 ; \mathrm{CI}=1.01-1.4$, respectively); however, only the relationship with self-reported moderate-to-severe asthma symptoms remained significant in the multivariate model $(\mathrm{OR}=1.2 ; \mathrm{CI}=1.1-1.4)$.

\section{DISCUSSION}

Psychological stress has been shown to worsen asthma (14), and PTSD has been associated with an increase in respiratory symptoms (15) and asthma (16). In this study, we documented a relationship between the psychological sequelae of the attacks and increased asthma severity and the utilization of urgent health care services 6 to 9 months after September 11. The increased reporting of physical symptoms including respiratory symptoms reported by individuals with PTSD may be related to a comorbid diagnosis of depression (15). In our study, however, the associations of depression with post-September 11 asthma severity were largely explained by adjustment for past asthma history and other covariates. Our findings suggest that while depression may be associated with more asthma symptoms in general, PTSD and posttraumatic stress symptoms may be better indicators of risk for worsening asthma after a traumatic event.

Although there is corroborating evidence from other studies that stress and PTSD are associated with reporting of increased respiratory symptoms, other physical symptoms, and health care utilization, the explanation for these relationships is unclear. It has been shown that hypocorticalism is common in individuals with PTSD and chronic stress, as well as individuals with asthma $(17,18)$. Wright and colleagues (14) reported on data demonstrating that stress reduces an individual's resistance to respiratory infectious agents explaining another potential causal link. Cohen (19) demonstrated that severe chronic stress was associated with an increase in developing a cold. $\beta$-adrenergic hyporesponsiveness and parasympathetic hyperresponsiveness have been demonstrated in individuals with both asthma (20) and PTSD (21). Stress and PTSD may also affect an individual's ability to

TABLE 2. Crude and Adjusted Relationships Between Psychological Outcomes and Asthma Severity and Utilization of Health Care Services

\begin{tabular}{|c|c|c|c|c|c|c|c|c|c|}
\hline & \multicolumn{3}{|c|}{$\begin{array}{l}\text { Moderate to Severe Asthma } \\
\text { Symptoms after September } 11\end{array}$} & \multicolumn{3}{|c|}{$\begin{array}{l}\text { Emergency Room Visit after } \\
\text { September } 11\end{array}$} & \multicolumn{3}{|c|}{$\begin{array}{l}\text { Unscheduled Physician Visit after } \\
\text { September } 11\end{array}$} \\
\hline & $\%$ & Crude & Adjusted $^{a}$ & $\%$ & Crude & Adjusted $^{b}$ & $\%$ & Crude & Adjusted $^{c}$ \\
\hline \multicolumn{10}{|l|}{ Peri-event panic attack } \\
\hline No & 21.9 & 1.8 & $1.3(0.6-2.9)$ & 10.3 & $2.9^{*}$ & $1.1(0.4-3.4)$ & 19.7 & $3.7^{\star \star}$ & $2.0(0.8-4.6)$ \\
\hline Yes & 33.6 & & & 25.3 & & & 47.4 & & \\
\hline \multicolumn{10}{|l|}{ Depression } \\
\hline No & 22.8 & 1.8 & $1.6(0.6-4.3)$ & 12.4 & 2.2 & $1.0(0.3-3.7)$ & 25.1 & 1.2 & $0.9(0.3-2.5)$ \\
\hline Yes & 34.6 & & & 23.9 & & & 28.7 & & \\
\hline \multicolumn{10}{|l|}{ PTSD } \\
\hline No & 22.5 & $3.4^{*}$ & $3.4(1.2-9.4)^{*}$ & 11.4 & $5.3^{*}$ & $6.6(1.6-28.0)^{*}$ & 23.2 & $4.0^{*}$ & $3.6(1.1-11.5)^{\star *}$ \\
\hline Yes & 49.4 & & & 40.4 & & & 54.6 & & \\
\hline Number of PTSD symptoms & & $1.2^{\star \star}$ & $1.2(1.1-1.4)^{\star *}$ & & 1.2 & $1.1(0.9-1.4)$ & & $1.2^{* *}$ & $1.1(1.0-1.3)$ \\
\hline
\end{tabular}

${ }^{a}$ Adjusted for age, gender, race, education, friend or relative killed during the September 11 terrorist attacks, on-site involvement, and severity of symptoms 4 weeks before September 11 .

${ }^{b}$ Adjusted for gender, race, income, education, life-time stressors, smells related to the September 11 terrorist attacks, on-site involvement, and ER visits before September 11.

${ }^{c}$ Adjusted for age, gender, race, income, education, witnessing the September 11 attacks in person, on-site involvement, and ER visits before September 11.

$* p<.05$.

$* * p<.01$. 
self-manage asthma and adhere to treatment, although research to support this is sparse (14). In addition, individuals experiencing psychological stress may be more likely than others to seek health care for physical symptoms. Thus, there appear to be both biological and behavioral pathways that might link PTSD and asthma severity, although their elucidation is beyond the scope of this study.

The findings in this report are subject to limitations, including a lack of objective measures to validate the selfreported measures of asthma severity and the cross-sectional design precluding demonstration of temporal or causal relations of asthma severity to psychological symptoms. The prevalence of asthma reported in our survey is similar to the prevalence estimated for New York State adults for 2001 (11.1\%) (22). Our sample of individuals living in close proximity to the WTC may not be representative of the population living there on September 11, because those individuals with severe asthma may have been more likely to move away and out of our sampling frame. Similarly, differential response rates by persons with and without psychological symptoms may affect the observed relations. However, our sample was comparable with expected census demographics, suggesting that we are reporting results on a representative sample of the population. In addition, this study was not designed to assess the environmental impacts of the September 11 terrorist attacks, which contributed to respiratory symptoms in the weeks after September $11(6,7)$ and to persistent respiratory illness in some of the most heavily exposed (4). Despite the lack of objective environmental measures, the fact that most of the study population lived outside the immediate impact zone and the fact that reported experience of smells related to the attacks in the week after September 11 did not account for the association between PTSD and asthma severity argues against this association being explained solely by environmental exposures or concerns. We only assessed the respiratory symptoms among those respondents who stated they had asthma. Therefore, we were not able to compare our findings in the population with asthma to a population, which had increased respiratory symptoms but no history of asthma. Finally, the lack of comparable surveys before September 11, 2001 and the seasonal variation in asthma severity preclude any estimate of the absolute impact of the terrorist attacks on overall asthma severity in the NYC region.

Notwithstanding these limitations, our findings add to previous evidence of increased rates of somatic symptoms and illness among persons with PTSD. This connection of psychologic stress symptoms to physical illness after mass trauma may represent a significant, although poorly documented, public health impact of the September 11 terrorist attacks. Researchers and health care providers working with populations impacted by the September 11 attacks should be attentive to the potential impact of posttraumatic stress on physical illness experienced by those populations.

\section{REFERENCES}

1. Galea S, Ahern J, Resnick H, et al. Psychological sequelae of the September terrorist attacks in New York City. N Engl J Med 2002;346: 982-987.

2. Schlenger WE, Caddell JM, Ebert L, et al. Psychological reactions to terrorist attacks: Findings from the National Study of Americans' Reactions to September 11. JAMA 2002;288:581-588.

3. Banauch G, McLaughlin M, Hirshhorn R, et al. Injuries and illness among New York City fire department rescue workers after responding to the World Trade Center attacks. MMWR Morb Mortal Wkly Rep 2002; 51:1-5.

4. Prezant DJ, Weiden M, Banauch GI, et al. Cough and bronchial responsiveness in firefighters at the World Trade Center site. N Engl J Med 2002;347:806-815.

5. Fagan J, Galea S, Ahern J, et al. Self-reported increase in asthma severity after the September 11 attacks on the World Trade Center-Manhattan, New York, 2001. MMWR Morb Mortal Wkly Rep 2002;51:781-784.

6. Ackelsberg J, Balter S, Bornschelgel K, et al. Syndromic Surveillance for Bioterrorism Following the Attacks on the World Trade Center-New York City, 2001. MMWR Morb Mortal Wkly Rep 2002;51(Special Issue): $13-15$.

7. Kramer R, Hayes R, Nolan V, et al. Community Needs Assessment of Lower Manhattan Residents Following the World Trade Center Attacks-Manhattan, New York City, 2001. MMWR Morb Mortal Wkly Rep 2002;51(Special Issue):10-13.

8. American Association for Public Opinion Research. 2000. Standard Definitions: Final Dispositions of Case Codes and Outcome Rates for Surveys. Ann Arbor, MI: AAPOR. Available at: http://www.aapor.org/ default.asp?page $=$ survey_methods/standards_and_best_practices / standard definitions.

9. Sherbourne CD, Stewart AL. The MOS social support survey. Soc Sci Med 1991;32:705-714.

10. Centers for Disease Control. Diagnostic Interview Schedule (DIS). In: Health Status of Vietnam Veterans. Supplement C: Medical and Psychological Procedure Manuals and Forms. Atlanta, GA: Centers for Disease Control; 1989:405-499.

11. Spitzer RL, Williams JBW, Gibbon M, et al. The structural clinical interview for DSM-III-R (SCID) I: history, rationale, and description. Arch Gen Psychiatry 1992;49:624-629.

12. Kilpatrick DG, Resnick HS, Freedy JR, et al. The posttraumatic stress disorder field trial evaluation of the PTSD construct-criteria A through E. In: Widiger T, Frances A, Pincus H, et al. (eds.) DSM-IV Sourcebook, Volume 4. Washington, DC: American Psychiatric Association Press; 1998:803-844.

13. Acierno R, Kilpatrick DG, Resnick M, et al. Assault, PTSD, family substance use, and depression as risk factors for cigarette use in youth: Findings from the National Survey of Adolescents. J Trauma Stress 2000;13:381-396.

14. Wright RJ, Rodriguez M, Cohen S. Review of psychosocial stress and asthma: an integrated biopsychosocial approach. Thorax 1998;53: 1066-1074.

15. McFarlane AC, Atchison M, Rafalowicz E, et al. Physical symptoms in post-traumatic stress disorder. J Psychosom Res 1994;38:715-726.

16. Weisberg RB, Bruce SE, Machan JT, et al. Nonpsychiatric illness among primary care patients with trauma histories and posttraumatic stress disorder. Psychiatr Serv 2002;53:848-854.

17. Yehuda R, Teicher MH, Trestman RL, et al. Cortisol regulation in posttraumatic stress disorder and major depression: a chronobiological analysis. Biol Psychiatry 1996;40:79-88.

18. Heim C, Ehlert U, Hellhammer DH. The potential role of hypocortisolism in the pathophysiology of stress-related bodily disorders. Psychoneuroendocrinology 2000;25:1-35.

19. Cohen S, Frank E, Doyle WJ, et al. Types of stressors that increase susceptibility to the common cold in healthy adults. Health Psychol 1998; 17:211-213.

20. Lemanske RF Jr, Kaliner MA. Autonomic nervous system abnormalities and asthma. Am Rev Respir Dis 1990;141:S157-S161.

21. Charmey DS, Deutch AY, Krystal JH, et al. Psychobiologic mechanisms of posttraumatic stress disorder. Arch Gen Psychiatry 1993;50:295-305.

22. Fritz PM, Recer G, Luttinger D. Asthma Among Adult New Yorkers. New York State Department of Health. http://www.health.state.ny.us/ nysdoh/brfss/pdf/brfss7_1.pdf. Accessed April 2, 2003 